\title{
Digital Media-based Health Intervention on the promotion of Women's physical activity: a quasi-experimental study
}

\author{
Nooshin Peyman ${ }^{1}$, Majid Rezai-Rad², Hadi Tehrani" ${ }^{*}$, Mahdi Gholian-Aval' ${ }^{1}$, Mohammad Vahedian-Shahroodi ${ }^{1}$
} and Hamid Heidarian Miri ${ }^{1}$

\begin{abstract}
Background: Technological advances have caused poor mobility and lower physical activity among humankind. This study was conducted to assess the impact of a digital media-based (multi-media, internet, and mobile phone) health intervention on promotion of women's physical activity.

Methods: In this quasi-experimental study, 360 women were divided into case and control groups. The digital media-based educational intervention was conducted in two months in the case group electronically, using mail and Internet and telephone platforms. Physical activity was measured using International Physical Activity Questionnaire (IPAQ) that estimated women's physical activity rate in the previous week. Data was analyzed using descriptive and analytical statistics (ANOVA, chi-square, paired and independent t-tests) using SPSS 20.
\end{abstract}

Results: The mean score of knowledge, attitude and level of physical activity in the control group were not significantly different before and after the intervention. While in the case group, this difference before and after the intervention was significant $(p<0.001)$, and mean scores of the above-mentioned factors increased after the intervention.

Conclusions: Using innovative and digital media-based health education can be effective in improving healthbased behavior such as physical activity. Therefore, it seems necessary to develop user-based strategies and strengthen the behavioral change theories and hypotheses based on digital media for effective influence on behavior.

Trial registration: Iranian Registry of Clinical Trials (IRCT), IRCT20160619028529N5. Registered December 24, 2017 [retrospectively registered].

Keywords: Health behavior, Health promotion, Physical activity, Women, Health education, Fitness, International physical activity questionnaire (IPAQ)

\section{Background}

For various reasons, nowadays people are having more sedentary lifestyle. Physical activity associated with work, home, and transportation has been decreased due to technological advancements and social changes [1]. Increased working hours has led to having less time performing physical activity Paying less attention to a more natural life and spread of urbanization have also attributed to reduced physical activity [2]. Ekelund et al. in 2016 showed that high levels of moderate intensity

\footnotetext{
* Correspondence: tehrani.hadi420@gmail.com

${ }^{1}$ Social Determinants of Health Research Center, Mashhad University of

Medical Sciences, Mashhad, Iran

Full list of author information is available at the end of the article
}

physical activity (i.e., about 60-75 min per day) eliminates the increased mortality risks associated with high total sitting time [3].

Physical activity is a viable strategy that can affect noncommunicable diseases. In 2005, 35 million deaths occurred due to non-communicable chronic diseases (NCDs) worldwide, comprising $60 \%$ of all deaths and $47 \%$ of the diseases [4]. According to a World Health Organization (WHO) report, these figures will reach 73\% (3/4 of all deaths) and $60 \%$ of the burden of diseases by 2020. This is even more serious in middle and low-income countries, and has turned into an epidemic that involves about $80 \%$ of deaths [5]. Ding et al. in 2016 showed that 
"low-income and middle-income countries share the largest disease burden from physical inactivity" [6].

The prevalence of obesity among women has been increased. This increase was due to the changes in lifestyles, increasing mechanization of tasks and dramatic decrease in physical activity. Benefits and impact of regular physical activity in promoting health are wellrecognized; therefore, interventions should be designed to encourage women to adopt, maintain and enhance such health behaviors [7].

Self-care behaviors, especially during physical activity, are recognized as important factors in maintaining an active lifestyle. Various studies have demonstrated that self-care behaviors are associated with promotion of health, increased physical activity, and weight loss [8].

A possible way to enhance self-care behaviors and increase participants' involvement in health-related behaviors is the use of digital media, such as the Internet, mobile phone technology, etc. [9]. Thus, in an attempt to increase current rates of physical activity in women, digital media can be used as an effective mechanism [10]. These digital media are promising because of potential for scalability, low cost, use in multiple settings including middle- and low-income nations, and opportunities for real-time modifications and improvements [9].

According to statistics provided by the International Telecommunication Union (ITU) in 2001, there were more than 20,000 health-related sites, and Internet users were estimated as 500 million people. In 2013, this union estimated Internet users as 2.3 billion, which is more than one-thirds of the world's population [11]. This rate was also estimated to be 3.2 billion Internet users in 2015 [12]. Accordingly, health education and promotion researchers throughout the world are currently trying to explore innovative ways based on the internet and other digital media to increase the efficacy of their interventions [13]. The study of Vollum in 2014 [14] showed that social interaction can be increased and enhanced by the use of social media in educational settings. Vollum's study [14] also showed that social media have already been using current programs of health/ wellness outside the K-12 system.

These media have some advantages including: availability at any time or place, providing efficient content and appropriate interaction with the user. Therefore, these media provide a good platform for people to monitor their health behaviors such as monitoring the level of physical activity to improve health [15]. Therefore, it seems that digital media-based intervention can increase physics activity.

Thus, given the highly important role of regular physical activity in improving women's life quality, and valuable women's role in forming an active family and social lifestyle, the present study was conducted to assess the impact of digital media-based intervention (multimedia, internet, and mobile phone) to promote women's physical activity.

\section{Methods \\ Design}

This was a quasi-experimental study. Its population was women who referred to health centers in Kerman, Iran. At the time of the study, there were 8 active health centers in Kerman, in which 4 were randomly selected as intervention centers and 4 as control ones.

\section{Sample}

According to the following formula, considering type 1 error of 0.05 and power of $80 \%$, and assuming $15 \%$ score difference before and after the intervention, 180 women were calculated as the sample size, and the same number as the control group. Therefore, 360 women were recruited.

$$
\frac{\left[z\left(1-\frac{\alpha}{2}\right) \sqrt{2 p(1-p)}+z\left(1-\beta \sqrt{p 0(1-p 0)+p 1(1-p 1)}^{2}\right.\right.}{(p 1-p 0)^{2}} \times D
$$

The members of the intervention group were selected from 4 health centers in Kerman. The samples were randomly selected from a list of women visiting the health centers and then the intervention was performed. Inclusion criteria were: being older than 18 years, having a mobile phone and the ability to use it, access to the internet, ability to use a computer and the internet, and willingness to participate. The invitation to participate in the study was sent electronically and/or by mobile to those who had the conditions to participate in the study. Given that centers were governmental, all people participated in the study willingly (Fig. 1).

\section{Measures}

Body mass index (BMI) was calculated using the respondents' reported height and weight. Physical activity was measured using the International Physical Activity Questionnaire (IPAQ) which estimates women's physical activity rate in regarding MET-minutes/week [16]. A separate questionnaire was used to investigate the knowledge and attitude. This questionnaire consisted of 12 questions. Six multiple choice questions were used to measure knowledge and six five-point Likert style (Completely agree, no idea, disagree, completely disagree) questions were used to measure attitudes. After preparing the knowledge and attitude questionnaire, content validity and face validity were performed to test the reliability of the instrument. A literature review was performed and experts and professors related to the subject of the study were consulted to edit the 


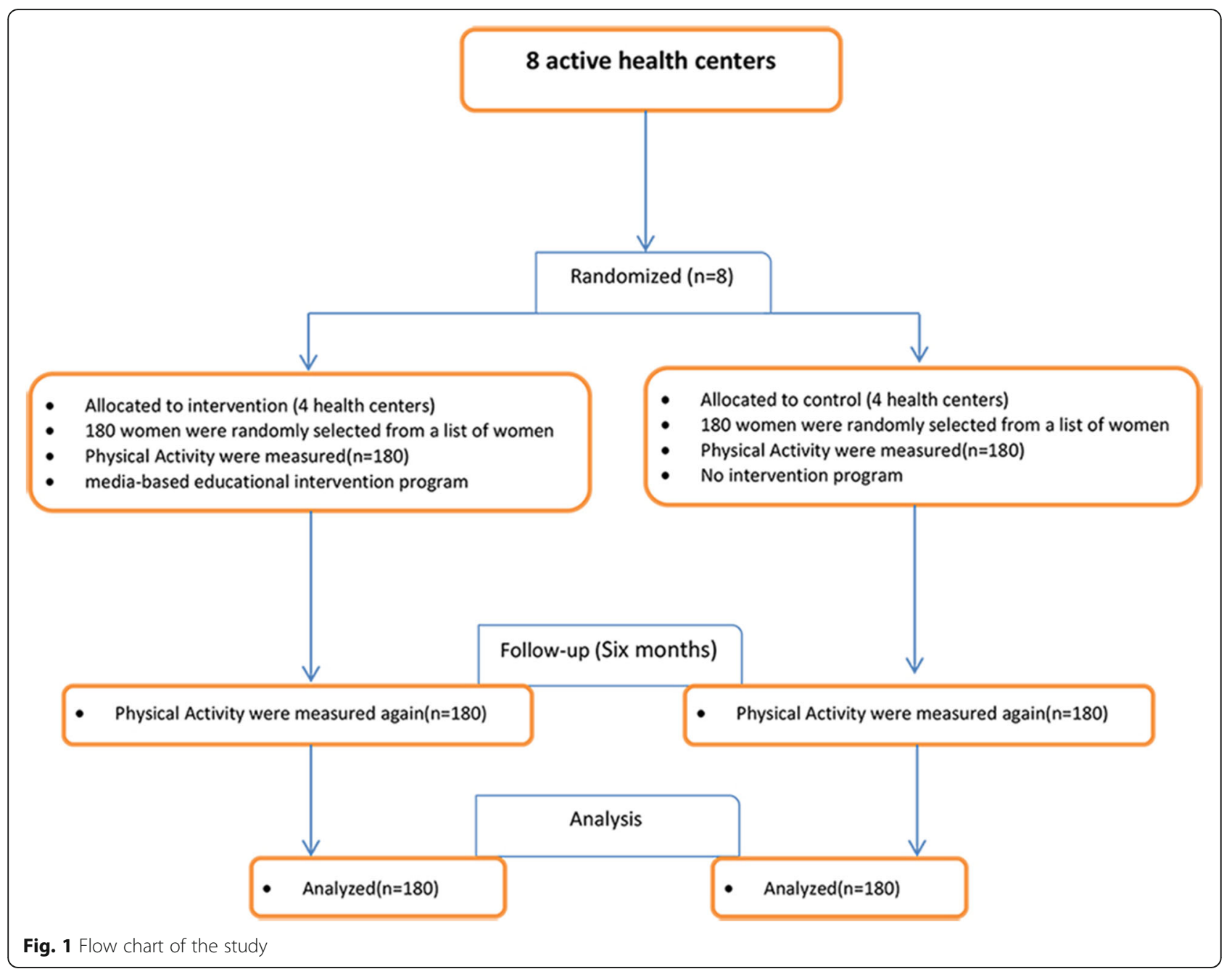

questionnaire. When the face validity of the instrument was verified, by using the content validity index (CVI) and content validity ratio (CVR), the questionnaire was sent to 10 experts in public health and health information technology; their comments and view were used to eliminate possible defects of the questionnaire. To test the validity of the questionnaire, Cronbach's alpha coefficient was used. The questionnaire was filled-out by 20 women referring to health centers in Kerman, Iran and was filled-out again after 2 weeks. The Cronbach's alpha coefficient of internal consistency of the questionnaire was estimated between $82 \%$ and $88 \%$ and its interclass correlation coefficient was $71-77 \%$.

\section{Analysis}

Data was then analyzed using descriptive (frequency distribution, mean and standard deviation) and analytical statistics such as ANOVA, paired and independent t-tests by $\mathrm{SPSS}_{20}$. A paired $t$-test was conducted to compare changes before and after the intervention. Two groups comparison was performed using Independent sample t-test.

\section{Intervention}

The unique characteristic of this study was its digital media-based electronic educational intervention. In the first step, the research team explained the importance and the objectives of the study to attract women's cooperation. Moreover, women were briefed on how to answer the questions using a completed typical questionnaire, and further explanations were also first given if needed. Data was collected at the first stage (pre-test), simultaneously, in all 8 centers.

When the pretest was completed, media-based educational intervention program was performed for the intervention group. Virtual space in this study was used in the following way. An educational website related to physical activity was designed with different sections. Besides different educational stuff related to physical activity, the advantages of such activities and regular exercises and educational films were also included. In 
Table 1 Frequency Distribution of Personal Details among Control and Case Groups

\begin{tabular}{|c|c|c|c|}
\hline Variable & Control group & Case group & $p$ \\
\hline \multicolumn{3}{|l|}{ Marital status } & \multirow{3}{*}{$\begin{array}{l}\mathrm{df}=1 \\
p^{* *}=0.147\end{array}$} \\
\hline Single & $68(37.2 \%)$ & $54(30 \%)$ & \\
\hline Married & $113(62.8 \%)$ & $126(70 \%)$ & \\
\hline \multicolumn{3}{|l|}{ Education level } & \multirow{5}{*}{$\begin{array}{l}\mathrm{df}=3 \\
p^{* *}=0.638\end{array}$} \\
\hline High school & $68(37.8 \%)$ & $58(32.2 \%)$ & \\
\hline Associate Degree & 17(9.4\%) & $22(12.2 \%)$ & \\
\hline$B S C$. & $77(42.8 \%)$ & 79(43.9\%) & \\
\hline MSc. \& above & $18(10 \%)$ & $21(11.7 \%)$ & \\
\hline Age & $31.933 \pm 9.458$ & $33.411 \pm 9.010$ & $p^{*}=0.130$ \\
\hline Height (cm) & $161.39 \pm 7.488$ & $162.38 \pm 5.738$ & $p^{*}=0.159$ \\
\hline Weight (kg) & $63.022 \pm 12.366$ & $67.288 \pm 11.958$ & $p^{*}<0.001$ \\
\hline Body Mass Index (BMI) & $24.353 \pm 5.576$ & $25.522 \pm 4.370$ & $p^{*}<0.05$ \\
\hline
\end{tabular}

addition to watch films on this site, women could download the films on regular mobile phones and use it. The site also had an electronic section in which women could assess their physical activity and BMI online and therefore, they were encouraged to self-monitor their physical activity. Due to the Iranian culture and religious beliefs of Muslim women and therefore restrictions of physical activity for women in every place, a section of the site was assigned to introduce suitable women-only places devoted to physical activity with photos and its characteristics, such as women-only parks, female-only sessions, female-only gyms and sport complexes, etc. To that end, an educational $C D$ with several chapters was prepared in an auto-run format according to the latest physical activity topics by the Ministry of Health and Medical Education of Islamic Republic of Iran. This CD was available for women participating in the study. Furthermore, an educational website on women's physical activity was designed with different sections. In addition to various trainings about physical activity and the benefits of regular exercise in the website, a page was designed for educational video clips, enabling women to watch videos, or download them on their mobiles. In the chat room section, participants could exchange information.
Mobile phone numbers of participants and people whose views had influence on the participants' physical activity (i.e. supporters) were also registered in the pretest. Then, SMS messages about the importance of physical activity were sent daily to supporters and participants. Six months after intervention, the impact of interventions was assessed and data collected using the same tools.

\section{Results}

The demographic and socioeconomic characteristics of the women are presented in Table 1. The two groups were not significantly different regarding demographic characteristics except for weight (Table 1).

Before the intervention, women's mean weight was $63.022 \mathrm{~kg}$ in the control group and $67.288 \mathrm{~kg}$ in the case group; there was a significant difference between the two groups $(p<0.05)$. However, after the intervention, mean weight decreased to $66.388 \mathrm{~kg}$ in the case group, but increased to $63.07 \mathrm{~kg}$ in the control group $(p<0.001)$. Before the intervention, no significant difference was found regarding other demographic characteristics.

Before the intervention, BMI was $24.353 \mathrm{~kg} / \mathrm{m}^{2}$ in the control group and $25.522 \mathrm{~kg} /$ in the case group; the difference between the two groups was significant $(p=0.028)$. After the intervention, BMI increased to $24.404 \mathrm{~kg} / \mathrm{m}^{2}$ in the control group, but the increase was not significant $(p=0.664)$ based on paired $\mathrm{t}$-test. In the case group, mean BMI decreased to $25.186 \mathrm{~kg} / \mathrm{m}^{2}$, which was statistically significant based on paired t-test $(p<0.001)$.

The results showed no significant differences between the two groups in terms of knowledge, attitude, and physical activity before the intervention. However, according to independent $\mathrm{t}$-test, the difference between the two groups was significant after the intervention $(p<0.05)$, and mean scores of the above- mentioned scales increased among the intervention group (Table 2).

The mean score of knowledge, attitude and level of physical activity in the control group was not significantly different before and after the intervention (Table 3). While in the case group, this difference before and after intervention was significant $(p<0.001)$, and mean scores of the above-mentioned scales increased after the intervention (Fig. 2).

Table 2 Mean and Standard Deviation of Women's Knowledge, Attitude, and Physical Activity among Control and Case Groups before and after Intervention

\begin{tabular}{|c|c|c|c|c|c|c|}
\hline \multirow[t]{2}{*}{ Variable } & \multicolumn{3}{|c|}{ Mean and Standard Deviation Before Intervention } & \multicolumn{3}{|c|}{ Mean and Standard Deviation After Intervention } \\
\hline & Control group & Case group & $p$-value & Control group & Case group & $p$-value \\
\hline Knowledge & $0.8156( \pm 0.0600)$ & $0.9611( \pm 0.641)$ & $p^{*}=0.099$ & $0.8636( \pm 0.0744)$ & $6.116( \pm 0.0600)$ & $p^{*}<0.000$ \\
\hline Attitude & $\begin{array}{l}16.15 \\
( \pm 2.54)\end{array}$ & $16.16( \pm 3.412)$ & $p^{*}=0.136$ & $\begin{array}{l}16.70 \\
( \pm 2.87)\end{array}$ & $21.10( \pm 2.747)$ & $p^{*}<0.001$ \\
\hline Physical activity (MET/min) & $838.44( \pm 96.781)$ & $992.17( \pm 83.302)$ & $p^{*}=0.229$ & $881.82( \pm 90.482)$ & $3604.32( \pm 271.195)$ & $p^{*}<0.001$ \\
\hline
\end{tabular}


Table 3 Mean and Standard Deviation of Women's Knowledge, Attitude, and Physical Activity before and after Intervention among each of the Control and Case Groups

\begin{tabular}{|c|c|c|c|c|c|c|}
\hline \multirow[t]{2}{*}{ Variable } & \multicolumn{3}{|l|}{$\begin{array}{l}\text { Control Group } \\
\mathrm{SD} \pm \mathrm{M}\end{array}$} & \multicolumn{3}{|l|}{$\begin{array}{l}\text { Case Group } \\
\mathrm{SD} \pm \mathrm{M}\end{array}$} \\
\hline & Before Intervention & After Intervention & $p^{*}$ & Before Intervention & After Intervention & $p^{*}$ \\
\hline Knowledge & $0.816( \pm 0.0600)$ & $\begin{array}{l}0.8636 \\
( \pm 0.0744)\end{array}$ & $p^{*}=0.586$ & $0.9611( \pm 0.641)$ & $6.116( \pm 0.0600)$ & $\overline{p^{*}<0.001}$ \\
\hline Attitude & $16.65( \pm 2.54)$ & $\begin{array}{l}16.70 \\
( \pm 2.87)\end{array}$ & $p^{*}=0.859$ & $\begin{array}{l}16.15 \\
( \pm 3.41)\end{array}$ & $21.10( \pm 2.74)$ & $p^{*}<0.001$ \\
\hline Physical activity & $838.44( \pm 96.781)$ & $\begin{array}{l}881.82 \\
( \pm 90.482)\end{array}$ & $p^{*}=0.566$ & $\begin{array}{l}992.17 \\
( \pm 83.302)\end{array}$ & $\begin{array}{l}3604.32 \\
( \pm 271.195)\end{array}$ & $p^{*}<0.001$ \\
\hline
\end{tabular}

*Paired $t$ test

Table 4 indicates that the effects of the intervention, time and the interaction of time and intervention are statistically significant for knowledge, attitude and physical activity. However, as it is illustrated in Table 3 the score of knowledge, attitude and level of physical activity are not considerably changed over two measurements among controls group. This could be explained by the significant effect of interaction between time and intervention that emphasizes the effect of time differs noticeably between cases and controls.

\section{Discussion}

This study was conducted to assess the impact of digital media-based (multimedia, internet, and mobile phone) intervention and education on women's physical activity. Use of cyberspace and digital technology in a specific group (Muslim women) was one of the most prominent features of this study compared to other studies conducted in this area especially in Iran.
Generally, before the intervention, control and case groups were similar regarding their demographic characteristics. The results showed a significant increase of physical activity of women who used educational multimedia and websites and received daily text messages, compared to those in the control group. This indicates a positive impact of media, as educational interventions, on health promotion.

Ornes and Ransdell [17] also investigated the effect of web-based education on female university students' physical activity who received education through internet for 4 weeks. By the end of the study, mean number of steps per day had increased by $38.8 \%$ among the group that received education through the internet; which indicates the positive effect of using internet and web on physical activity. The result of this study concurs with the results of Ornes and Ransdell's investigation.

With rapid growth of digital media, including internet and mobile phones, and increasing number of people

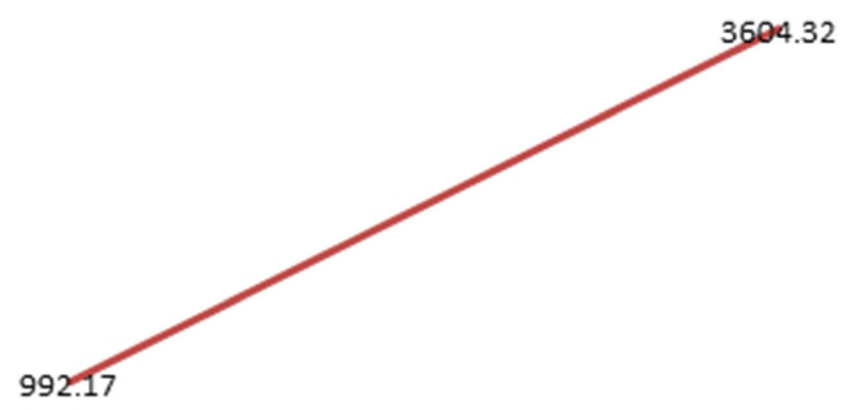

$838.44-884.82$

Before Intervention

After Intervention

Control Group Case Group

Fig. 2 Mean of Women's Physical Activity before and after Intervention in Control and Case Groups 
Table 4 Results from repeated measure analysis of variance for knowledge, attitude physical activity

\begin{tabular}{|c|c|c|c|c|c|c|c|c|c|}
\hline \multirow[b]{2}{*}{ Source } & \multicolumn{3}{|c|}{ Knowledge } & \multicolumn{3}{|c|}{ Attitude } & \multicolumn{3}{|c|}{ Physical Activity } \\
\hline & $\mathrm{F}$ & P-value & Adjusted R-squared & $\mathrm{F}$ & P-value & Adjusted R-squared & $F$ & P-value & Adjusted R-squared \\
\hline Model & 10.44 & 0.0000 & 0.8266 & 2.44 & 0.0000 & 0.4222 & 2.91 & 0.0000 & 0.4893 \\
\hline intervention & 864.49 & 0.0000 & & 68.19 & 0.0000 & & 47.91 & 0.0000 & \\
\hline time & 1071.5 & 0.0000 & & 144.59 & 0.0000 & & 94.52 & 0.0000 & \\
\hline intervention $\times$ time & 1034.37 & 0.0000 & & 150.19 & 0.0000 & & 85.13 & 0.0000 & \\
\hline
\end{tabular}

with access to such media use of these media seems necessary to encourage physical activity [18]. The strength of these media, compared to print media and face-to-face intervention, is educating large numbers of people at low costs [19].

In the present study, in addition to a significant increase in physical activity in the case group, women's knowledge and attitude also significantly increased after the intervention; while no increase was observed in the control group. This shows that digital media, such as internet, computer software, and mobile phone-based programs, encourage women to perform physical activity, and increase their knowledge and attitude.

Knowledge, attitude and behavior in our daily lives are intertwined with each other. Changes in knowledge cause changes in attitude. Change in attitude also causes changes in behavior. Educational programs with using digital media, such as internet, computer software, and mobile phone-based ones are effective in improving knowledge and attitudes to more physical activity [17] .

Palmer et al. [20] also conducted a web-based intervention among students. Palmer et al. study showed students' increased attitude and knowledge about physical activity, and indicated the positive effect of internetbased intervention on their knowledge and attitude.

Knowledge of the risks and benefits of lifestyleassociated behaviors are the prerequisites of performing a behavior. If people lack the relevant knowledge, they will not accept reasons for enduring difficulties associated with that behavior [21]. Digital media are capable of providing information in the shortest possible time with maximum efficiency, and have a huge impact on knowledge, literacy, and attitudes of their audience [22].

Another important result of the present study was about BMI variations before and after the intervention. Although two groups' BMI showed a significant difference before and after the intervention, BMI had a significant drop in the case group, after the interventions, and a slight increase in the control group. Thus, digital media caused increasing physical activity, which decreased in weight and an improvement in BMI in the case group.

In a study performed by Cavallo et al. [23] to assess the effect of social media-based intervention on physical activity, physical activity and social support increased in the case group and $66 \%$ of the participants recommended the use of digital media-based programs to their friends. Bennett et al. [24] also showed that internetbased weight loss interventions can be useful. In their study, they used interventions based on the internet and mobile phone for 12 weeks, which led to weight loss in the group that received education through the internet and mobile phone. Furthermore, weight loss was more prominent in participants who used more internet interventions.

\section{Strengths and limitations}

Strengths of this study were using virtual space and mobile phones for promotion of physical activity that provided the space for exchanging ideas and suggestions by participants. Limitations of the present study were low speed and narrow internet bandwidth and, sometimes, internet disconnection. Another limitation of this study was that the study was conducted only among women, thus findings from this study cannot be generalized to the general population. In addition, given that data collection was based on self-reporting there was the possibility of bias in a more favorable response and moreover, physical activity was not objectively assessed via a physical activity assessment or activity trackers.

\section{Conclusion}

It seems that media-based interventions (multimedia, internet, and mobile phone) can positively affect physical activity of women. Therefore, it seems essential to develop user-based strategies and strengthen behavioral change theories and hypotheses based on digital media by developing virtual and digital media use in the community.

\section{Abbreviations \\ BMI: Body mass index; IPAQ: International Physical Activity Questionnaire}

\section{Acknowledgements}

We express our gratitude to the management of Kerman University of Medical Sciences (KUMS) and its deputy of health, personnel of medical centers and all those who contributed to this study.

Funding

No financial support was received for this study.

Availability of data and materials

Data and materials can be requested from the corresponding author. 


\section{Authors' contributions}

HT designed and implemented of the project. NP conducted all of the literature searches. M V-h and H H-m were analyzed of data. M Gha prepared the first draft of the paper. M R-r reviewed the full-texts of the papers for data extraction. All authors read and approved the final manuscript.

\section{Ethics approval and consent to participate}

The present study was accepted by the ethics committee of Mashhad University of Medical Science. Written informed consents were obtained from all the study participation. Moreover, they were assured that all the information would be kept confidential and would not be revealed unless for research purposes and in an anonymous form. Participants were allowed to decline participation at any stage of the investigation.

\section{Consent for publication}

Not applicable

\section{Competing interests}

The authors declared no competing interests

\section{Publisher's Note}

Springer Nature remains neutral with regard to jurisdictional claims in published maps and institutional affiliations.

\section{Author details}

'Social Determinants of Health Research Center, Mashhad University of Medical Sciences, Mashhad, Iran. ${ }^{2}$ Health Care Management, Visiting Professor of Faculty of Management, Islamic Azad University, South Tehran Branch, Tehran, Iran.

Received: 8 February 2017 Accepted: 2 January 2018

Published online: 15 January 2018

\section{References}

1. Matson-Koffman DM, Brownstein JN, Neiner JA, Greaney ML. A site-specific literature review of policy and environmental interventions that promote physical activity and nutrition for cardiovascular health: what works? Am J Health Promot. 2005;19(3):167-93.

2. Mazloomy Mahmoodabad SS, Tehrani H, Gholian-aval M, Gholami H, Nematy M. The effect of social class on the amount of salt intake in patients with hypertension. Blood Press. 2016;25(6):360-3.

3. Ekelund U, Steene-Johannessen J, Brown WJ, Fagerland MW, Owen N, Powell KE, Bauman A, Lee I-M, Series LPA, Group LSBW. Does physical activity attenuate, or even eliminate, the detrimental association of sitting time with mortality? A harmonised meta-analysis of data from more than 1 million men and women. Lancet. 2016:388(10051):1302-10.

4. Bélanger M, Sabiston CM, Barnett TA, O'Loughlin E, Ward S, Contreras G, O'Loughlin J. Number of years of participation in some, but not all, types of physical activity during adolescence predicts level of physical activity in adulthood: results from a 13-year study. Int J Behav Nutr Phys Act. 2015;12(1):76

5. Koohpayehzadeh J, Etemad K, Abbasi M, Meysamie A, Sheikhbahaei S, Asgari F, Noshad S, Hafezi-Nejad N, Rafei A, Mousavizadeh M. Genderspecific changes in physical activity pattern in Iran: national surveillance of risk factors of non-communicable diseases (2007-2011). Int J Public Health. 2014;59(2):231-41.

6. Ding D, Lawson KD, Kolbe-Alexander TL, Finkelstein EA, Katzmarzyk PT, van Mechelen W, Pratt M, Committee LPASE. The economic burden of physical inactivity: a global analysis of major non-communicable diseases. Lancet. 2016;388(10051):1311-24

7. Taggart J, Williams A, Dennis S, Newall A, Shortus T, Zwar N, Denney-Wilson E, Harris MF. A systematic review of interventions in primary care to improve health literacy for chronic disease behavioral risk factors. BMC Fam Pract. 2012;13(1):49.

8. O'Neill JR, Liese AD, McKeown RE, Cai B, Cuffe SP, Mayer-Davis EJ, Hamman RF, Dabelea D. Physical activity and self-concept: the SEARCH for diabetes in youth case control study. Pediatr Exerc Sci. 2012;24(4):577-88.

9. Filion AJ, Darlington G, Chaput J-P, Ybarra M, Haines J. Examining the influence of a text message-based sleep and physical activity intervention among young adult smokers in the United States. BMC Public Health. 2015;15(1):671.
10. Marks JT, Campbell MK, Ward DS, Ribisl KM, Wildemuth BM, Symons MJ. A comparison of web and print media for physical activity promotion among adolescent girls. J Adolesc Health. 2006;39(1):96-104.

11. Bernhardt JM, Chaney JD, Chaney BH, Hall AK. New Media for Health Education. Health Educ Behav. 2013;40(2):129-32.

12. Facts I. Figures-the world in 2015. Geneva: The International Telecommunication Union (ITU); 2015.

13. Bauman A, Chau J. The role of media in promoting physical activity. J Phys Act Health. 2009;

14. Vollum MJ. The potential for social media use in K-12 physical and health education. Comput Hum Behav. 2014:35:560-4.

15. Ventola CL. Social media and health care professionals: benefits, risks, and best practices. Pharm Ther. 2014:39(7):491.

16. Hagströmer M, Oja P, Sjöström M. The international physical activity questionnaire (IPAQ): a study of concurrent and construct validity. Public Health Nutr. 2006;9(06):755-62.

17. Ornes $L$, Ransdell LB. Web-based physical activity intervention for college-aged women. Int Electron J Health Educ. 2007:10:126-37.

18. Chou W-yS, Prestin A, Lyons C, Wen KY. web 2.0 for health promotion: reviewing the current evidence. Am J Public Health. 2013;103(1):e9-e18.

19. Hieftje K, Edelman E, Camenga DR, Fiellin LE. Electronic media-based health interventions promoting behavior change in youth: a systematic review. JAMA Pediatr. 2013;167(6):574-80

20. Palmer S, Graham G, Elliott E. Effects of a web-based health program on fifth grade Children's physical activity knowledge, attitudes and behavior. Am J Health Educ. 2005:36(2):86-93.

21. Kollmuss A, Agyeman J. Mind the gap: why do people act environmentally and what are the barriers to pro-environmental behavior? Environ Educ Res. 2002;8(3):239-60.

22. Burke-Garcia A, Scally G. Trending now: future directions in digital media for the public health sector. J Public Health. 2014;36(4):527-34.

23. Cavallo DN, Tate DF, Ries AV, Brown JD, DeVellis RF, Ammerman AS. A socia media-based physical activity intervention: a randomized controlled trial. Am J Prev Med. 2012;43(5):527-32.

24. Bennett GG, Herring SJ, Puleo E, Stein EK, Emmons KM, Gillman MW. Web-based weight loss in primary care: a randomized controlled trial. Obesity. 2010;18(2):308-13.

\section{Submit your next manuscript to BioMed Central and we will help you at every step:}

- We accept pre-submission inquiries

- Our selector tool helps you to find the most relevant journal

- We provide round the clock customer support

- Convenient online submission

- Thorough peer review

- Inclusion in PubMed and all major indexing services

- Maximum visibility for your research

Submit your manuscript at www.biomedcentral.com/submit
Biomed Central 